\title{
Improved ETA-II Accelerator Performance
}

John Weir

This paper was prepared for submittal to the

1999 Particle Accelerator Conference

New York City, New York

March 29 - April 2, 1999

March 22, 1999

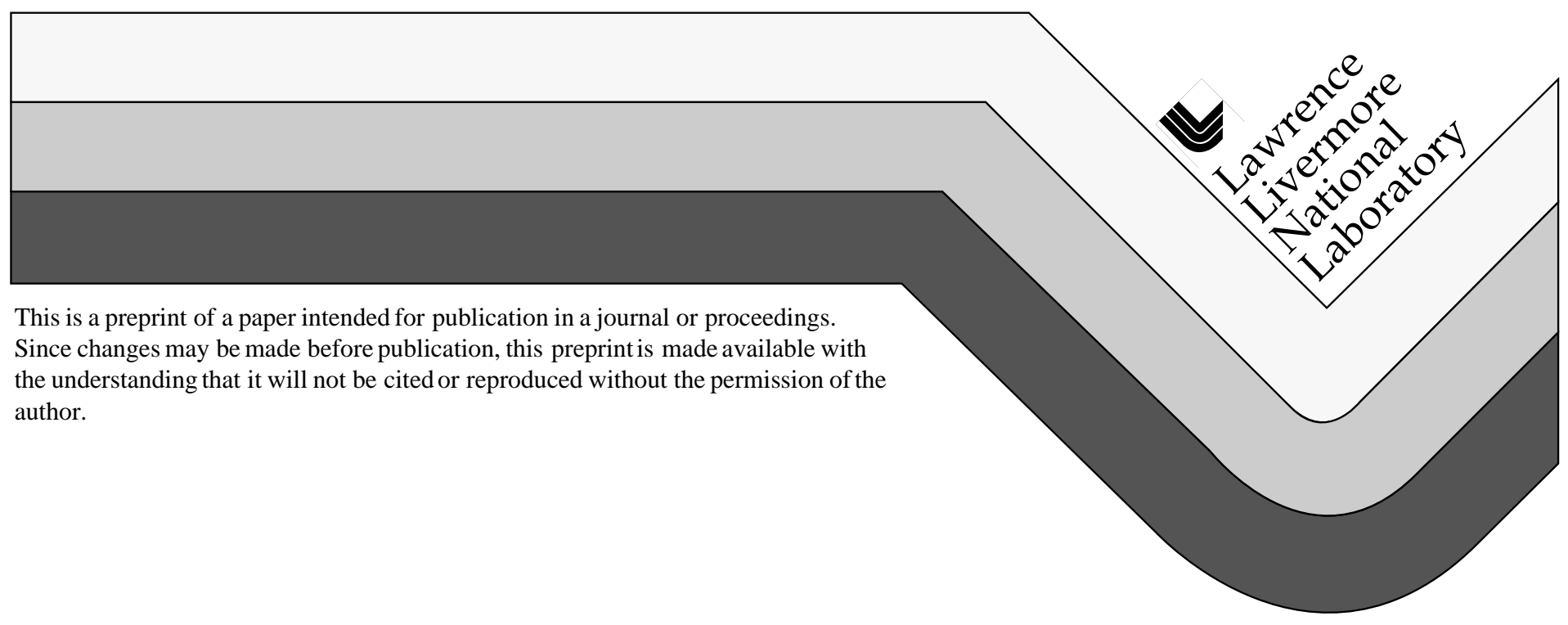




\section{DISCLAIMER}

This document was prepared as an account of work sponsored by an agency of the United States Government. Neither the United States Government nor the University of California nor any of their employees, makes any warranty, express or implied, or assumes any legal liability or responsibility for the accuracy, completeness, or usefulness of any information, apparatus, product, or process

disclosed, or represents that its use would not infringe privately owned rights. Reference herein to any specific commercial product, process, or service by trade name, trademark, manufacturer, or otherwise, does not necessarily constitute or imply its endorsement, recommendation, or favoring by the United States Government or the University of California. The views and opinions of authors expressed herein do not necessarily state or reflect those of the United States Government or the University of California, and shall not be used for advertising or product endorsement purposes. 


\title{
IMPROVED ETA-II ACCELERATOR PERFORMANCE
}

\author{
J. T. Weir, J. K. Boyd, Y-J Chen, J. C. Clark, D. L. Lager \\ and A. C. Paul, LLNL* \\ Abstract
}

Improvements have been made in the performance of the ETA-II accelerator that allow a nominal $2 \mathrm{kA}, 6 \mathrm{MeV}$ beam to be focused to a spot size less that $1 \mathrm{~mm}$ in diameter. The improvements include reducing the energy sweep to less than +/- $0.5 \%$ over $40 \mathrm{~ns}$ of the pulse using a real time energy diagnostic and improving the magnetic tune of the accelerator to reduce the emittance to 8 cm-mrad. Finally, an automated tuning system (MAESTRO) was run to minimize the time dependent centroid motion (corkscrew) by adjusting the steering dipoles over the focusing solenoids. The corkscrew motion was reduced to less than $+/-0.5 \mathrm{~mm}$ at the output of the accelerator.

\section{INTRODUCTION}

The Lawrence Livermore National Laboratory (LLNL) has begun using the Experimental Test Accelerator (ETA II) to study beam/target interactions at the $\mathrm{x}$-ray converter target for multiple shot, flash radiography experiments. The issues being studied involve the interaction of the electron beam with the plasma that forms on the initial shot and how the plasma affects the focusing and therefore spot size of subsequent shots. Typical multipulse x-ray experiments will use pulse spacings of 200 to 700 nanoseconds. ETA II cannot run at a repetition rate high enough to simulate multiple shots on target so we have used a laser to produce a plasma to simulate the first "shot" and the ETA II electron beam as the next shot in the sequence. To correctly simulate the effects that will occur in DARHT 2 or the proposed Advance Hydrotest Facility (AHF) we needed to achieve a beam spot density $25.5 \mathrm{Ka} / \mathrm{cm}^{2}$. This corresponds to focusing the $2 \mathrm{Ka}$ beam into a spot size of less than $1 \mathrm{~mm}$. FWHM. This tight focus was only possible after improvements were made to emittance, energy uniformity, centroid motion of the beam, and shot to shot repeatability.

\section{EMITTANCE}

Using standard pepper pot techniques the emittance of the ETA II accelerator was measured at $12 \mathrm{~cm}$-mrad when it was first decommissioned. This is real emittance measured in rr' space (un-normalized with no factor of $\pi$ ). Earlier measurements of the cathode brightness suggested the transport of the beam was leading to increased emittance. Modeling the injector and the first 10 cell block of the accelerator with the DPC and ST codes showed that in order to transport the low energy leading and trailing edges of the current pulse we were running the first anode magnet too low. This allowed us to catch the low energy part of the pulse without over focusing but required a mismatched condition on the higher energy center portion of the beam. By relaxing the constraint of maintaining all current through the first cell block, we were able to adjust the magnetic profile to give a smoother match to high energy portion of the beam. Using the improved injector matching and by hand tweaking the rest of the accelerator around the theoretical $\mathrm{B}_{\mathrm{z}}$ profile we were able to reduce the emittance to $8 \mathrm{~cm}$. mrad. at the end of the accelerator. Because the final beam spot size is dependent on emittance, this $30 \%$ reduction in emittance reduced our spot size by $20 \%$.

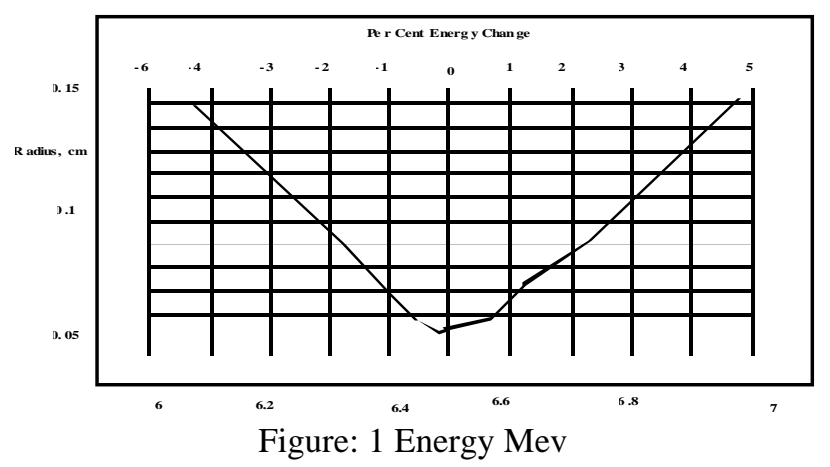

\section{ENERGY UNIFORMITY}

Beam spot size is a strong function of the beam energy. Figure 1 shows the spot size variation as a function of the energy for the final focusing magnet used in our target experiments. ETA II was designed to give an energy flattop of about 40 ns.. Adjustments to the energy uniformity are made by adjusting the timing between the four MAG D1 units that power that injector and the accelerator gaps. Moving the timing of the accelerator pulse power with respect to the injector will change the beam loading and skew the energy flatness. Because the 70 ns. beam pulse needs to fit closely under the $70 \mathrm{~ns}$. accelerating pulse these timing shifts are done in $0.25 \mathrm{~ns}$. steps. Since there are a large number of ways to time the accelerator MAG D1 units with respect to the injector, we wrote a program that displays the reduced data from the energy analyzer system on a real time display in the control room. The data is displayed as a percent diviation from the nominal beam energy. By observing the changes in a real time mode and adjusting the timing of the pulse power units we were able to reduce the energy variation across the flattop portion of the pulse to better than +/$0.5 \%$. Figure 2 shows the energy varriation across the center 40 ns. of our beam pulse. 


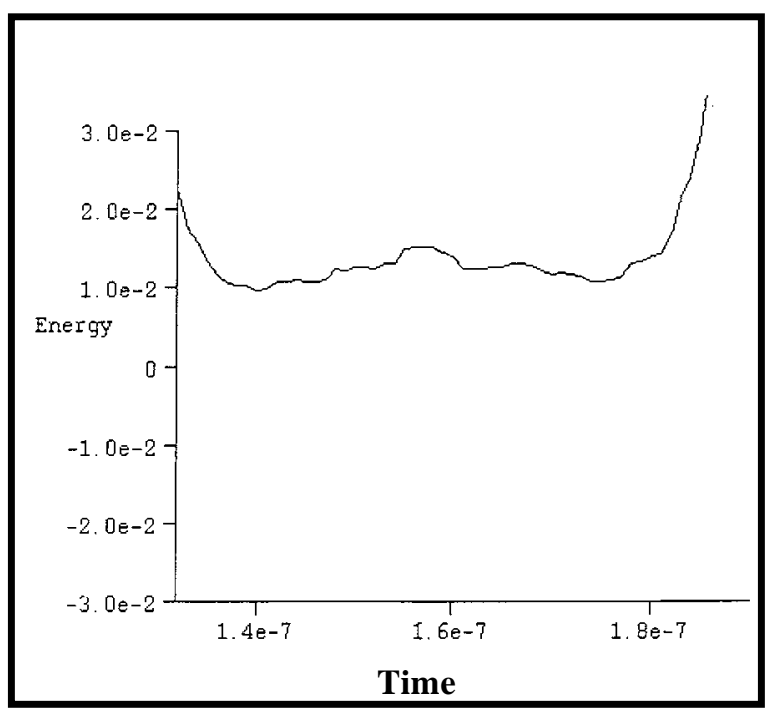

Figure: 2 Energy Variation

\section{BEAM CEMTROID MOTION}

Beam centroid motion (corkscrew) will also cause an effective growth in the final beam spot size. Corkscrew is caused by a combination of energy variations in the beam and traversing the focusing magnets off the center axis. Minimizing the corkscrew is accomplished by tuning the steering magnets that are wrapped around each of the solenoid magnets in the accelerator. We have developed an automated tuning system, MAESTRO, that can tune the entire accelerator steering system in about one hour. Modeling of our tuning system showed an error in our basic approach to adjusting the steering coils. There are twenty steering coils on each ten cell block (an $\mathrm{x}$ and a y coil for each solenoid) but only one pair of resistive wall monitors (beam bugs) after each ten cell block. In our old mode of operation, we would tune each pair of steering coils and work our way through the cell block trying to maintain the beam on center at the end of the cell block. Simulations showed it was very easy to get the beam oscillating through the cell block with larger and larger steering corrections needed to bring the beam back to center. By using only the steering at the first cell to bring the beam through on center and the steering at the last cell to remove the angle we were able to avoid large excursions through the cell block. It can be shown analytically that this is all the steering that is necessary to reduce the corkscrew to a minimum. Figure 3 shows the data from our beam bug at the end of the accelerator. The data is taken from a single shot and is the radial excursion of the beam centroid. The forty data points inside the 1 $\mathrm{mm}$. radius circle are the beam centroid position at $1 \mathrm{~ns}$. intervals through the $40 \mathrm{~ns}$. of beam flattop.

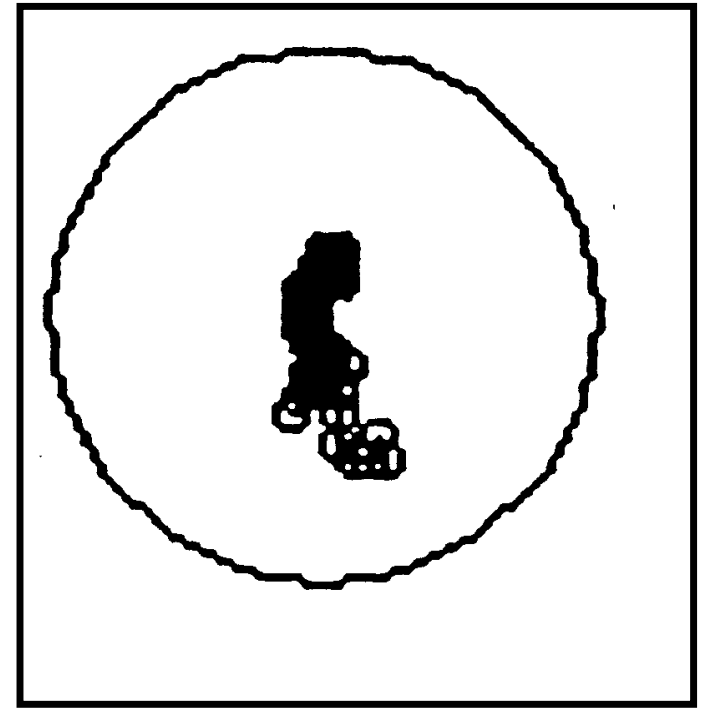

Figure : 3 Centroid Motion Inside a 1mm Radius Circle

\section{SHOT TO SHOT REPEATABILITY}

Historically, ETA II was designed to run in a burst mode at $5 \mathrm{KHz}$. This required large capacitor banks to store the energy and complex charging and switching circuitry to run the MAG 1D units at this repetition rate. We have removed the capacitor banks and the charging and switching circuitry and replaced them with off the shelf, well regulated power supplies. This has eliminated the largest source of shot to shot jitter on the accelerator. In our new configuration we have reduced the timing jitter on the pulse power units to below $+/-0.25 \mathrm{~ns}$. This is below the incremental step size of the timing adjustment and gives the accelerator excellent shot to shot repeatability.

\section{CONCLUSIONS}

By improving the emittance, energy uniformity, corkscrew motion, and the shot to shot repeatability on ETA II, we have been able to focus a $2 \mathrm{Ka}$ electron beam into a spot with a diameter of less that $1 \mathrm{~mm}$. 


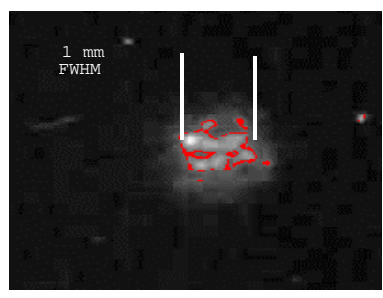

1

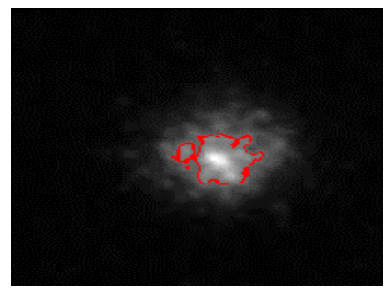

3
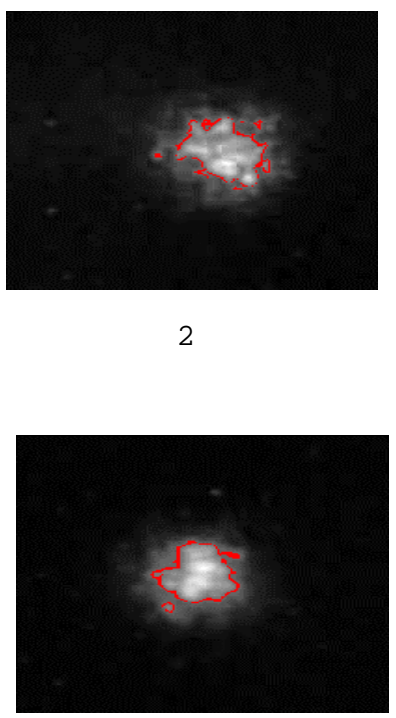

4

Figure: 4 Time Resolved X-Ray Images, 10 ns. Spacing

Figure 4 shows a time resolved xray image of the beam hitting a 0.005 inch thick Ta. Target. With energy desities produced by such beams we will be able to continue studying beam/target interactions for multipulse radiography.

*This work was performed under the auspices of the U.S. Department of Energy by the Lawrence Livermore National Laboratory underContract No.W-7405-Eng-48.

\#Email:weir2@1lnl.gov 